\title{
Study on Chinese College Students' Stereotypes of the Origin of Telephone Brands
}

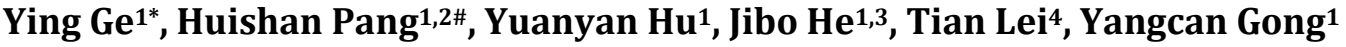 \\ ${ }^{1}$ Key Laboratory of Emotion and Mental Health in Chongqing, Chongqing University of Arts and Sciences, Chongqing \\ Collaborative Innovation Center for Brain Science, Chongqing, China \\ ${ }^{2}$ School of Education Science, Minnan Normal University, Zhangzhou, China \\ ${ }^{3}$ Department of Psychology, Wichita State University, Wichita, USA \\ ${ }^{4}$ Department of Industry Design, School of Mechanical and Science and Engineering, Huazhong University of Science and \\ Technology, Wuhan, China \\ Email: *gy8620@163.com, "amor919edu@163.com
}

How to cite this paper: Ge, Y., Pang, H. S., Hu, Y. Y., He, J. B., Lei, T., \& Gong, Y. C. (2018). Study on Chinese College Students' Stereotypes of the Origin of Telephone Brands. Chinese Studies, 7, 72-81.

https://doi.org/10.4236/chnstd.2018.71007

Received: January 28, 2018

Accepted: February 23, 2018

Published: February 27, 2018

Copyright () 2018 by authors and Scientific Research Publishing Inc. This work is licensed under the Creative Commons Attribution International License (CC BY 4.0).

http://creativecommons.org/licenses/by/4.0/

\begin{abstract}
The study aims to investigate Chinese college students' stereotypes of the origins of telephone brands, by interviewing 80 college students about their attitudes toward Chinese and foreign telephone brands and analyzing the reasons concerned. The study finds that college students indeed hold stereotypes about the origin of telephone brand and show preference to domestic telephone brands. In particular, appearance design is what they will first take into consideration when choosing telephone brands.
\end{abstract}

\section{Keywords}

Telephone Brands, Stereotypes of Origins, Qualitative Interview

\section{Foreword}

In the context of economic globalization, brand has become a significant means for enterprises to ensure their competitive edges in the market. As an intangible asset capable of enhancing value, it is designed to differentiate one organization or product from its rivals by means of name or symbol. The value of a brand is subject to the impression of consumers on the brand (Li, 2011). As mobile internet is in the midst of booming development nowadays, telephones, the terminal products of mobile communications industry, are witnessing their market competition turning white-hot. In China, foreign brands occupy larger market shares by virtue of high price and quality, than domestic brands with high cost performance. This fact shows that consumers hold stereotypes about the origins 
of telephone brands at home and abroad. Accounting for a major part of telephone users, college students are more sensitive to new-generation products and technologies than other groups of users. Given the financial dependence, their consumption behaviors however are subject to economic capability, underlined by unique tendencies and features. This study aims to investigate Chinese college students' stereotypes of the origins of telephone brands and inform the building of brand image from a new perspective. At present, this study is only able to conduct preliminary analysis of gender effect; further exploration is needed to gain a better understanding of intergroup differences and other groups' external validity.

\section{Literature Review}

Stereotype is a social cognitive structure comprising knowledge or thoughts to represent the entire group of individuals or behaviors as a whole (Wang, 2002). As a special social cognitive schema, stereotype is a kind of cognitive phenomenon which showcases people's unchanged attitude toward some people, matters or objects after being influenced by related social factors. The field of study on stereotype is extensive, involved in gender, ethnic, occupation, age, subject, region and others (Wang \& He, 2015). In recent years, researchers have turned their attention to brand stereotype. Jin Xin indicates that quality of foreign TV brands is better than that of domestic ones in the eyes of Chinese consumers (Jin, 2008); Li Dawei launches a study on college students' attitude toward luxury brand. His study reveals that college students prefer luxury brand to ordinary one (Li, 2012); Zhao Jing also discovers that, in the eyes of consumers, clothing brands sold online seem quite low in price and quality, riddled with deceit (Zhao, 2015).

There have been few studies on the stereotype of origin and relevant literatures that clearly put forward such concept by now. Similar concepts, like country-of-origin stereotype (Jiang, Wang, \& Chen, 2013), place-of-origin stereotype (Li, Zhang, \& Tang, 2015), preconceived notion of place-of-origin (He \& Liu, 2014), embody place-of-origin effect generated from brands and national and regional identification implied (Wang \& Zhao, 2004). Related study confirm that consumers are partial to products made in developed countries rather than those from underdeveloped countries (Vrlegh \& Steenkam, 1999); like consumers in developing countries, American consumers show preference for international brands (Dimofte, Johansson, \& Ronkainen, 2008). Wang Shaojun is the first in China to explicitly use the concept of "stereotype of origin" in his study literatures. He defines the stereotype of origin in itself as consumers' stable view, image and cognition of special products made in a particular country or region. Such stereotype is hardly recognized and changed under normal circumstances, for instance, the stable impression on French perfumes and Swiss watches (Wang, 2010; Wang, 2011). The generation of such stereotype is closely linked to social culture of a country or region and show a consistency with the social cul- 
ture. In addition, individual's stereotype will be deepened and strengthened in the course of social interaction (Janna \& Rao, 1997).

Based on thinking about above theories and by sorting out existing study achievements on telephone brands, we discover that 1) in terms of study content, main difference between domestic and foreign telephone brands mainly lies in product quality and service as well as enterprise image (Jiao, 2007). Value of telephone brands is usually contingent on brand popularity, preference, association and loyalty (Li, 2011). Key performance of telephone and enterprise brand image are two decisive factors of brand loyalty (Han, 2012; Xu \& Wang, 2016). Foreign telephone brands enjoy higher reputation than domestic ones (Guo, 2012). For foreign nationals resident in China, the effect of place-of-origin of Chinese telephone brands based on herd mentality tends to shore up their intention of purchase (Fan, 2017). The telephone brands experience is proportional to the purchase intention (Lei, 2016). Authors of these study achievements have made preliminary study on telephone brands. However, they haven't elaborated on the stereotype of brand and origin yet; 2 ) as for study object, study objects are randomly selected for difference comparison of telephone brands and influence factor of brand value, while only college students are investigated during the study in brand loyalty and reputation. Studies concerning college students, who account for a large portion of telephone consumers, are only a few to count.

From the above, the study is launched based on following basic thought: college students, main consumer group of telephone market, are regarded as the study object, qualitative interview as the main study approach and stereotype of origin of telephone brand as core content of the study. If the assumption that Chinese college students indeed hold stereotype of domestic and foreign telephone brands is reliable, the different preference for telephone brands exists.

\section{Methods}

\subsection{Participants}

A total of 15 students are randomly selected from a college based in western China to participate in the pilot interview. In later formal interview, 80 students (the female and male accounting for 40 respectively) are selected from other three colleges. All students are required to involve in similar interview for the first time.

\subsection{Methods}

In the study, qualitative interview is adopted to investigate consumers' concern and selection of telephone brands as well as their reasons. An interview is a conversation where questions are asked, answers are given and recorded for exploration of social condition, with specific purpose and structure (Steinar \& Svend, 2009). In the interview, interviewer raises questions to interviewees, according to specified outline and theme and by use of some tools such as interview outlines and voice recorder. Interviews range from open-ended, semi-structured and 
structured conversations. Study-based interview may be influenced by cultural difference and thus emphasis shall be put on question formulation, tone and design of questions (Meng, 2004). Interview is widely applied in sociology, pedagogy, psychology, economics, management and other fields for data collection (Chai, 1994).

\subsection{Interview Process}

1) Interview preparation

Before the formal interview, a voice recorder and a roller ball pen as well as an A4 paper shall be prepared. The lab shall be free of any noise, to ensure interviewees' clear grasp of questions raised by interviewer and serious thinking of such questions, and high-quality recording. Face-to-face interview shall conducted, which helps interviewer better observe the interviewee in their conversation.

2) Pilot interview

Pilot interview was launched in December 2016 before formal interview. At this stage, 15 interviewees were involved in the pilot interview, for the sake of modifying and upgrading the interview outline. Pilot interview is designed to assess impact of each question listed in interview outline on study results, before formal large-scale interview. The major method is to set up an independent study group comprising five members. All members shall respectively encode documents related to above 15 interviewees with different serial numbers in the lab, then make a discussion over the result through summary, and formulate the ultimate interview outline after modification.

3) Formal interview

Three interviewers were arranged in the study. According to the ultimate outline modified after pilot interview, they engaged 80 interviewers in separate interview from January to March 2017. Interview content was divided into two parts: interviewees' preference for domestic telephone brands or foreign ones, and the names of their loved ones; the reason why they prefer these brands and sharing of their personal experiences. By interviewees' consent, interviewers could record their conversion but should not interrupt interviewees during the interview.

\section{Data Processing}

After the formal interview was finished, 80 effective textual documents were formulated according to above recorded materials, and encoded by five researchers assessing materials developed in the pilot interview. After separately encoding all textual materials, five researchers summarized and classified contents encoded by themselves. By dividing dimensions, they calculated the scorer reliability, which showed the consistency of encoders stood at $77.65 \%$. The Five-point Likert Method was adopted in data processing, with five levels ranging from "strongly disagree" to "strongly disagree". This helped encoders score 
the answers of study objects in each dimension. Final scores of study objects were made in the dimension after integrating all scores of five encoders (Deng, 2014). Al last, all final scores of interview contents in different dimensions were imported in the SPSS18.0 for statistics and analysis. In the meantime, $\mathrm{G}_{*}$ Power 3.1.9.2 is deployed to calculate the effect sizes of data and analyze the statistical power.

\section{Results}

\subsection{Selection of Telephone Brands}

According to above interview targeted to 80 interviewees, top five Chinese telephone brands and top five foreign ones are selected. They are Xiaomi, Meizu, Huawei, ZTE and OPPO in China, and Apple, Samsung, BlackBerry, Nokia and Sony outside China.

\subsection{Result of Chi-Squared Test}

The interview with 80 interviewees finds that both female and male interviewees show the similar preference $(p>0.05)$ for brands in the Chi-Squared Test. In detail, preference rates for the female and the male are $50.1 \%$ and $50.8 \%$ respectively in terms of Chinese brands; and are $49.9 \%$ and $49.2 \%$ respectively as far as foreign brands. On the whole, $53.0 \%$ of interviewees prefer Chinese telephone brands and believe that Chinese telephone brands are superior to foreign ones; $37.9 \%$ of interviewees show the preference for foreign telephone brands and they give similar reason; $9.1 \%$ interviewees like two categories at the same time, or vice versa. There are significant difference among the numbers of interviewees respectively preferring Chinese and foreign telephone brands and others. However, the number of interviewees preferring domestic ones heads the list. ( $p<$ $0.001, d=0.188$, statistical power $=1.000)($ Table 1$)$.

\subsection{Classification of Data Encoding, Example Sentence about Influence Factors}

According to interview materials, three aspects of factors influencing interviewees' selection for telephone brands are summarized, including 15 categories: influence of others, popularity, herd mentality, brand image and patriotism (social factor); comfort, personal preference, consuming capacity, individual demand and personal experience (personal factor); and practicability, appearance design, the quality of telephone, cost performance and operation speed (telephone factor). By means of data encoding, above factors are listed in the Table 2 and attached with example sentences. The Five-point Likert Method is adopted in the study which includes variations in five levels, namely, "strongly disagree = 1 ", " disagree $=2$ ", "neutral = 3", "agree $=4$ ", and "strongly agree $=5$ ".

\subsection{The Variance Analysis of the Coded Variables}

The table of the variance analysis of each factor in choosing telephone brands 
Table 1. Attitudes of interviewees toward telephone brands.

\begin{tabular}{ccc}
\hline Attitude & Number of Interviewees & $\chi^{2}$ \\
\hline Preference for Chinese Brands & $53.0 \%$ & $30.02^{\star * *}$ \\
Preference for Foreign Brands & $37.9 \%$ & \\
Others & $9.1 \%$ & \\
\hline
\end{tabular}

Note: ${ }^{*} p<0.05,{ }^{* *} p<0.01,{ }^{* * *} p<0.001$.

Table 2. Classification of data encoding and example sentence.

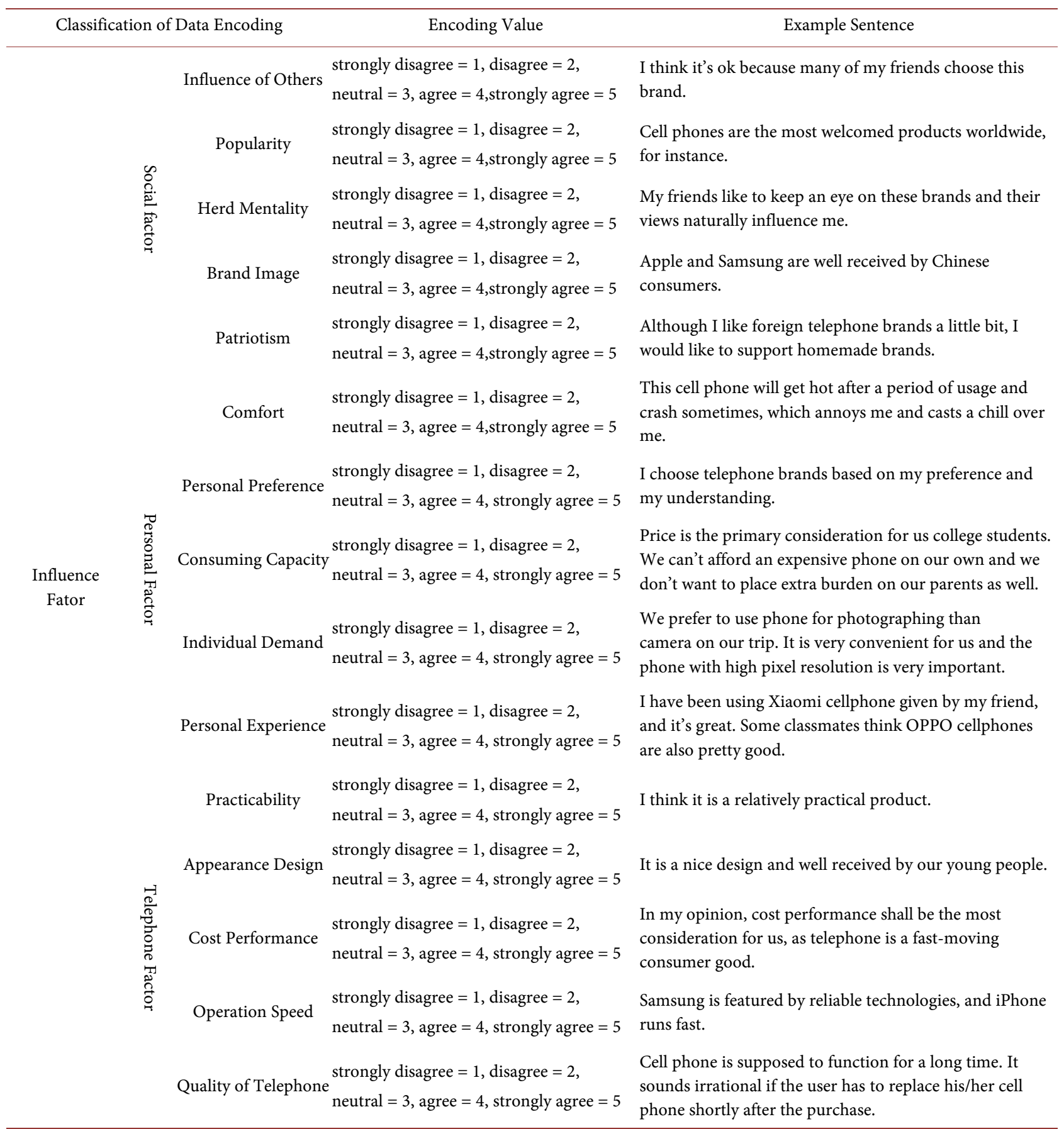


(Table 3) indicates that appearance design is significantly different $(F=4.59, p<$ $\left.0.05, \eta_{p}^{2}=0.156\right)$. The power of the statistical test is 0.042 . Hence, appearance design is a crucial factor in choosing telephone brands. Meanwhile, there is a marginal significant relationship between brand image and the study objects $\left(F_{1}\right.$ $\left.=2.58, p=0.08, \eta_{p}^{2}=0.058\right)$; the power is 0.313 . And the same relationship exists between operation speed and the object telephone brands $\left(F_{2}=2.67, p=\right.$ $\left.0.08, \eta_{p}^{2}=0.059\right)$ with the power of 0.315 .

\section{Discussion}

\subsection{The Choice of Telephone Brands}

The top five Chinese brands and overseas brands were listed respectively according to the brands mentioned by college students in the interviews. Nokia, though its glory has faded away, still holds a place in customers' preference. As a classic brand, Nokia has played an indispensable role in the mobile communication of Chinese over the past decades, according to the description of subjects in the extensive interview. Nokia to Chinese is more than a telephone brand but an epitome of dream and memory witnessing the development of Chinese telephone brands. Moreover, BlackBerry stays active among the top ones despite of its small market share in mainland China. The subjects who are passionate about science and technology give the credit to the technical indexes and functions of BlackBerry in later intensive interviews.

Table 3. Variance analysis of each factor in choosing telephone brands.

\begin{tabular}{crrrrr}
\hline \multirow{2}{*}{ Variables } & Chinese Brands & Overseas Brands & Others & \multirow{2}{*}{$F$} & \multirow{2}{*}{$P$} \\
\cline { 2 - 4 } & $M \pm S D$ & $M \pm S D$ & $M \pm S D$ & & \\
\hline Influence of Others & $2.06 \pm 1.50$ & $2.01 \pm 1.42$ & $1.67 \pm 1.30$ & 0.19 & 0.83 \\
Popularity & $1.67 \pm 1.11$ & $1.88 \pm 1.30$ & $1.08 \pm 0.20$ & 1.19 & 0.31 \\
Herd Mentality & $1.51 \pm 0.78$ & $1.74 \pm 1.11$ & $1.13 \pm 0.21$ & 1.26 & 0.29 \\
Brand image & $1.79 \pm 0.84$ & $2.38 \pm 1.45$ & $1.50 \pm 1.22$ & 2.58 & 0.08 \\
Patriotism & $1.33 \pm 0.84$ & $1.09 \pm 0.24$ & $1.00 \pm 0.00$ & 1.38 & 0.26 \\
Comfort & $1.99 \pm 1.14$ & $1.95 \pm 1.02$ & $2.33 \pm 1.32$ & 0.30 & 0.75 \\
Personal Preference & $2.61 \pm 1.18$ & $2.89 \pm 1.08$ & $2.42 \pm 1.33$ & 0.62 & 0.54 \\
Personal Experience & $2.61 \pm 1.28$ & $2.20 \pm 0.74$ & $2.63 \pm 1.60$ & 1.01 & 0.37 \\
Consuming Capacity & $1.66 \pm 1.08$ & $1.25 \pm 0.80$ & $1.17 \pm 0.41$ & 1.75 & 0.18 \\
Individual Demand & $2.34 \pm 0.85$ & $2.48 \pm 0.96$ & $2.83 \pm 1.51$ & 0.71 & 0.50 \\
Practicability & $2.18 \pm 0.93$ & $1.87 \pm 0.69$ & $2.58 \pm 1.37$ & 1.84 & 0.17 \\
Appearance Design & $1.86 \pm 1.34$ & $3.05 \pm 1.70$ & $2.29 \pm 1.55$ & $4.59 *$ & 0.02 \\
the Quality of Telephone & $2.31 \pm 1.11$ & $2.38 \pm 1.30$ & $2.67 \pm 1.41$ & 0.22 & 0.81 \\
Cost Performance & $2.35 \pm 1.58$ & $1.67 \pm 0.98$ & $2.33 \pm 1.32$ & 1.92 & 0.16 \\
Operation Speed & $1.27 \pm 0.45$ & $1.61 \pm 0.98$ & $1.92 \pm 1.13$ & 2.67 & 0.08 \\
\hline
\end{tabular}

Note: ${ }^{*} p<0.05,{ }^{* *} p<0.01,{ }^{* * *} p<0.001$. 


\subsection{The College Students' Preference for Chinese Telephone Brands}

The interviews manifest college students' penchant for Chinese telephone brands. Some students said: "As a Chinese, I prefer Chinese mobile phones." and "We should support domestic brands as they are blossoming these years." The shared social and cultural elements of certain country and nation offer the local customers a sense of convergence to a certain extent which leads customers to prefer domestic brands with national identity, ethnocentrism, and a sense of superiority (Watson \&Wright, 2000). The study supports the finding of previous studies that the Tendency exists among the masses including cyber citizens, adolescents, and college students (Matevž et al., 2016; Li \& Zhang, 2015; Wang et al., 2016; Ran, 2010; Wu \& Zhu, 2010). Other studies show that customers have cognitive differences towards different brands. Domestic brands give them a sense of morality while foreign brands make them feel approachable (Zhang, 2017). Mental factors including patriotism and national pride as the virtues highly praised by the public stress the superiority of choosing domestic brands; therefore, customers incline to domestic products in spite of the better-quality overseas products.

\subsection{Appearance Design Significantly Weighs with Chinese College Students' Choice of Telephone Brands}

The study also finds that the telephone itself is the main reason for Chinese college students to make their choices. The appearance design of telephone is a vital factor, followed by operation speed and brand image. The effect of operation speed, one of telephone performances, on college students choosing telephone brands shown in the study supports the previous findings (Han, 2012; Xu \& Wang, 2016); appearance design has leaped to the top factor, which reflects the new trend in telephone market. Representative, stylish, and individual, Chinese college students of the new era are the mainstream of consumption. The consuming characters of Chinese college students are follows: 1) pursuing novelty and distinction, college students are particular about fashion tide and sensitive to latest products and technologies, thus laying extra emphasis on the sense of fashion and appearance of mobile phones (Guo, 2006). 2) As a consumer group without income, college students take account of the price of telephones. The subjects in the study mainly are from western China where the economy cries for development. Thus the price is one of the top concerns of them. 3) The independence and dependence of consumption behavior together manipulate college students. Perceptual consumption defeating rational consumption brings college students impulse and emotional buying (Hao \& Zhou, 2012; Yin, 2012); while the surge of self-consciousness make the young vulnerable to the outside effects including the opinions of others (Li, 2014). Hence, the telephone brand with eye-catching appearance, prominent quality, reasonable price and brilliant brand image is the favorite of Chinese college students to meet the demands for aesthetic quality and practicability. 


\section{References}

Chai, Z. R. (1994). Application Problems of Interview in Investigation of Sociology, Social Psychology and Integrated Application. Management Observer, No. 4, 56-57.

Deng, X. M. (2014). Why Ethical Consumers Don't Do What They Say: The Study on Factors Influencing Consumers' Ethical Buying Intention-Behavior Gap. Acta Psychologica Sinica, 46, 1014-1031. https://doi.org/10.3724/SP.J.1041.2014.01014

Dimofte, C. V., Johansson, J. K., \& Ronkainen, I. A. (2008). Cognitive and Affective Reactions of U.S. Consumers to Global Brands. Journal of International Marketing, 16, 113-135. https://doi.org/10.1509/jimk.16.4.113

Fan, K. (2017). The Effects of Images of the Origins on Purchase Intention: Regulatory Roles of Herd Mentality. East China Normal University.

Guo, H. J. (2012). Study on the Brand Reputation of Domestic Telephone among Chinese College Students. Market Modernization, No. 9, 25-27.

Guo, S. (2006). Analysis and Marking Strategy of Telephone Market in College Students. Journal of Shanxi University of Finance and Economics, No. S2, 57-58.

Han, J. S. (2012). Empirical Analysis of Telephone Brand Loyalty of Taiyuan College Students. Shanxi University of Finance \& Economics.

Hao, Z. H., \& Zhou, Z. (2012). Study on the Consumption of Contemporary College Students and Educational Strategy. Market Modernization, No. 7, 54.

He, X. Z., \& Liu, D. B. (2014). Research on the Place-of-Origin Stereotype and Consumer Behavior Model. Journal of Systems Engineering, 29, 160-170.

Janna, S., \& Rao, C. P. (1997). The Effect of Country-of-Origin related Stereotypes and Personal Beliefs on Product Evaluation. Psychology and Marketing, 14, 689-702. https://doi.org/10.1002/(SICI)1520-6793(199710)14:7<689::AID-MAR4>3.0.CO;2-C

Jiang, H. Y., Wang, H. Z., \& Chen, Z. X. (2013). The Effects of Mental Processing Mode on the Changeover of Country-of-origin Related Stereotypes-How to View the "New Clues" of Emerging Countries. Journal of Sun Yatsen University (Social Science Edition), 53, 189-200.

Jiao, L. (2007). Comparative Research on Chinese and Overseas Telephone Brand Images-An Empirical Research Based on A.L.Biel Model. Shandong University.

Jin, X. (2008). Experimental Research on Consumers' Implicit Stereotype of the Quality of Television Brands. Northeast Normal University.

Lei, X. X. (2016). Empirical Research of the Effects of Telephone Brand Experience on Consumers Purchase Intention. Soochow University.

Li, D. W. (2012). Study on College Students' Social Attitude towards Luxury Brands. East China Normal University.

Li, D., Zhang, Y., \& Tang, G. (2015). Research on the Relationship between Consumers' Interaction and the Image of Brand Origins. Commercial Research, 57, 116-122.

Li, L., \& Zhang, Y. (2015). What Determines Cyber Citizens' Boycott on Overseas Products? The Demonstration of Influencing Factors in Ethnocentrism of Chinese Online Consumers. New Media and Society, No. 2, 232-242.

Li, Y. (2011). Study on the Influencing Factors in Brand Value Based on Customer's Purchase Decision. Kunming: Kunming University of Science and Technology.

Li, Y. (2014). Study on College Students' Preference for Telephone Brands. Xi'an: Xidian University.

Matevž, R., Ding, Z., Škare, V., Došen, Đ. O., \& Žabkar, V. (2016). Comparing Consumer 
Innovativeness and Ethnocentrism of Young-Adult Consumers. Journal of Business Research, 69, 3682-3686. https://doi.org/10.1016/j.jbusres.2016.03.029

Meng, H. (2004). Research Interview and Its Application Status and Prospect. Psychological Science, 27, 1202-1205.

Ran, N. (2010). Empirical Study on Consumer Ethnocentrism Tendency-Based on the Comparison between Middle School Students and College Students. China Youth Study, No. 2, 5-9.

Steinar, K., \& Svend, B. (2009). Interviews: Learning the Craft of Qualitative Research Interview. Thousand Oaks, CA: Sage.

Vrlegh, P. W. J., \& Steenkamp, J. B. E. M. (1999). A Review and Meta-Analysis of Country-of-Origin Research. Journal of Economic Psychology, 20, 521-546. https://doi.org/10.1016/S0167-4870(99)00023-9

Wang, H., \& Zhao, P. (2004). Country of Brand Effect: An Empirical Study in China and Its Marketing Managerial Implications. China Industrial Economy, No. 1, 78-86.

Wang, P. (2002). Theory and Research on Stereotype. Lanzhou: Gansu Education Press.

Wang, P., \& He, W. (2015). Social Cognitive Psychology. Beijing: Beijing Normal University Press.

Wang, S. (2010). Experimental Research on College Students' Stereotype of the Origin Place of Laptop. Wuhu: Anhui Normal University.

Wang, S. (2011). Implicit Research on College Students' Stereotype of the Origin Place of Laptop. Journal of Jincheng Institute of Technology, 4, 85-88.

Wang, T., Shu, R., Shen, Z. et al (2016). The Consumer Ethnocentrism Tendency of Chinese College Students-On the Basis of the Data of Actual Brand Purchasing Behavior. Jiangsu Commercial Forum, No. 9, 181-183.

Watson, J. J., \& Wright, K. (2000). Consumer Ethnocentrism and Attitudes toward Domestic and Foreign Products. European Journal of Marketing, 34, 1149-1166. https://doi.org/10.1108/03090560010342520

Wu, J., \& Zhu, N. (2010). Empirical Research on the Effect of Adolescent Consumer Ethnocentrism on Purchase Intention-An Exploration of Theory of Reasoned Action. Youth Studies, No. 2, 44-51.

$\mathrm{Xu}, \mathrm{D} ., \mathrm{\&}$ Wang, H. (2016). Research Report on the Influencing Factors in Telephone Brand Loyalty-From the Perspective of College Students. Market Modernization, No. 3, 12-13.

Yin, C. (2012). Analysis of Commodity Packaging Design Catering for College Students' Consuming Behavior. Market Modernization, No. 7, 88-89.

Zhang, X. (2017). Study on Consumers' Cognitive Differences towards Domestic Brands and Foreign Brands. Guilin: Guilin University of Electronic Technology.

Zhao, J. (2015). Study on the Stereotype and Rebranding of the Clothing Brands in Chinese Online Market. Beijing: Beijing Jiaotong University. 